\title{
Importance of Ethical Decision Making; Application of James Rest Model
}

\author{
Uzma Khursheed", Sana Sehar, Muhammad Afzal
}

Lahore School of Nursing, the University of Lahore Pakistan

\author{
DOI: $10.36348 /$ sjnhc.2019.v02i12.007 \\ | Received: 05.12.2019 | Accepted: 16.12.2019 | Published: 28.12.2019 \\ *Corresponding author: Uzma Khursheed

\section{Abstract}

Ethical decision-making in an organization is an important process. Decision-making requires careful assessment and analysis of all possible alternatives. It is the management executives ' duty at all levels. In this case study, patient suffered due to medical harm and ethical committee did not provide justice to patient. Ethical decision-making model apply on this scenario. James Rest (1994) developed theoretical framework for understanding the process of ethical decision making. His model has four components: moral awareness, moral motivation, moral judgement and moral action. Thomas Jones gave moral intensity model in 1991. Jones concluded that the moral features, which he collectively called moral strength, affect ethical decision-making. Jones conceptualized his model so that moral strength could impact each of the Rest's Four Component Model components. Organization leaders faces moral complex situation, their consciousness of the moral conflict, their decisions on choices and consequences, and their ability to act are significantly affected by the particular aspects of the moral situation. The priniciple of ethical decision making must be followed while taking a decision.

Keywords: Ethics, Decision Making, Autonomy, Justice.

Copyright @ 2019: This is an open-access article distributed under the terms of the Creative Commons Attribution license which permits unrestricted use, distribution, and reproduction in any medium for non-commercial use (NonCommercial, or CC-BY-NC) provided the original author and source are credited.

\section{INTRODUCTION}

Ethics is the organized study of morals - a branch of philosophy that basically considers what is "right," "wrong," "good" or "bad" and, most significantly, all of the "grey areas" when stressed with the best possible decision. Ethical decision-making refers to the method of assessing choosing among options in way reliable with moral guideline. The five principle of ethical decision making includes autonomy, justice, beneficence, nonmaleficence, veracity and fidelity $[1,2]$. The process of making ethical decision making requires: commitment, awareness, and competency. It is both moral and effective to make good decisions. Ethics crosses religious and cultural lines and aims to make fair and informed decisions in all aspects of human behavior [3].

\section{CASE SCENARIO}

A patient admitted in private hospital for surgery. After surgery, doctor's team decides for epidural insertion to control his pain. Written consent was taken for this procedure. Epidural inserted ate the level of T-10, T-11. After few hours, patient complaining of low sensation in lower limbs. Doctor examined him and noticed that his lower limbs were paralyzed. After inquiring, it was identified this because of wrong epidural insertion. This issue went to ethical committee. Ethical committee investigates the issue. It turns out the doctor's fault. Patient belongs to poor family. The case remains unsolved; no action was taken against doctor because their team was strong enough to suppress the matter. They satisfied the patient by saying this "It is your disease complication". The patient did not get justice by ethical committee.

\section{Ethical Decision Making: The Four Component Model}

James Rest's [4] theoretical framework for understanding the mechanism of ethical decisionmaking evolved from a desire to collect ideas and analysis from a variety of perspectives on moral development and behavior. Rest argued that while moral judgment is important, it is not the only influence on ethical decision-making, nor the most relevant. Rest indicates that ethical decision-making requires four different psychological processes: moral awareness, moral judgment, moral motivation / intention, and moral character / action. 
Moral sensitivity (moral awareness), as defined by Rest [4], refers to the ability of an individual to recognize that there is a moral issue in a situation. Recognizing a moral issue involves the knowledge of the person that his / her behavior will hurt and/or help others. Later research expands this concept, indicating that moral tolerance is the awareness by the decisionmaker that a situation has moral content and that a moral perspective is therefore valid [5]. According to my scenario, medical error with patient lead to ethical injustice. The patient's autonomy was not taken into account. Decision making committee broke the principle of nonmaleficence and veracity.

Moral judgment refers to formulating and assessing the moral justification for possible solutions to the moral issue. This step in the process requires reasoning to determine which ethically sound choices and possible consequences. According to scenario, ethical committee formulates the conference just for the patient satisfaction. After rule out the medical error, accurate decision was not taken for patients' autonomy.

Moral motivation (moral intention) refers to the intention of making a moral choice over a different value option. This aspect of ethical decision-making includes contributing to the moral value of choice. For example, an individual may consider two solutions to a problem, one leading to an increase in personal power and the other morally correct. In this case, the intention of the person to choose the value of morality over the value of power is moral motivation. In scenario, Ethical committee focuses on the personal power while deciding and didn't care for the patient's moral intention. They didn't follow the principle of ethical decision making (beneficence and fidelity).

Moral courage (moral action) refers to the actions of a person. This element is the action in the circumstance of the individual. This step involves boldness, commitment, and the ability to make a moral decision. In scenario, after medical error patient treat symptomatically. Committee defend themselves by saying this to patient "It is your disease complication".
No action taken against doctor. Committee did not make any guidelines to prevent this incidence in future. They did not do justice with patient.

Rest [4] recommended that each component is separate and can affect the others. In addition, failure at any stage can lead to a failure to make an ethical decision. An individual may have strong moral judgment abilities but will not start using them if they lack moral awareness and fail to identify a moral issue.

\section{Moral Intensity}

The lack of research on the features of a moral problem initiated the development of the model of moral intensity by Thomas Jones [6]. Jones concluded that the moral features, which he collectively called moral strength, affect ethical decision-making. Jones conceptualized his model so that moral strength could impact each of the Rest's Four Component Model components. The six dimensions of moral intensity are Magnitude of Consequences, Temporal Immediacy, Social Consensus, Proximity, Probability of Effect, and Concentration of Effect. The magnitude of consequences refers to the extent to which an individual can be harmed or benefit from the action of the decision-maker. Temporal Immediacy refers to the duration of the action and its consequences. Social Consensus refers to a social group's degree of agreement that an action is either good or bad. A strong social consensus that an act is morally wrong increases the intensity of morality. Proximity refers to the decision-maker's closeness to those who may be influenced by the effects. The probability of effect refers to the expectation that the anticipated outcomes will occur and the estimated rate of harm / benefit. The final dimension, Effect concentration refers to the relationship between the number of people affected and the severity of the harm. All dimension increases moral intensity and they effect on ethical decision making [6].

The four-step model shown here incorporates the principles of both Rest and Jones and is one way to make realistic, rational decisions easily, consciously and deliberately (Figure 1).

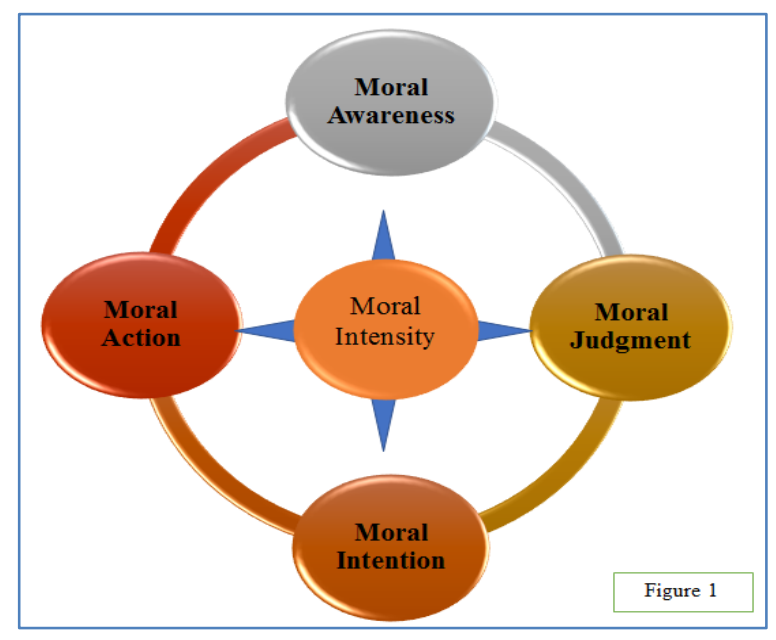




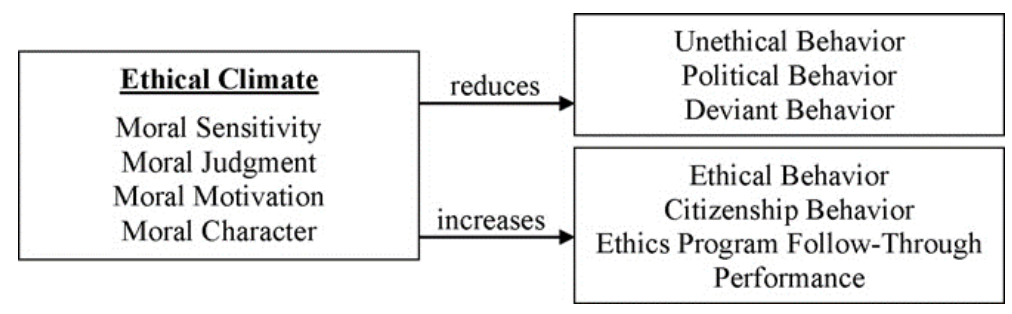

\section{RESULTS (In light of Cause and Effect)}

Patient-centeredness is described, as "providing care that is compassionate and inclusive of individual patient interests, needs and values and ensuring that patient values drive all clinical decisions. Its goal seeks to improve health outcomes by closing the gap between patient demands and their medical needs. Patient-centered care dimensions include improving health literacy through information and education; care coordination and integration; physical comfort; emotional support; and personalized care that includes the concept of shared decision-making [7].

It is common for medical errors and injustices to result from personal interaction with leaders of the healthcare delivery system (individual level) as well as from the complexity of interactions between compound agents within the regulated system in which the patient care / treatment process (system level) takes place. This makes the correlations between person and system levels with respect to "good professional judgment" and "deviations" from "best practices" and "good care" particularly significant for the potential of a connection between errors and social injustices. Medical-related harms have been discussed in the sense of integrity, the development of trustworthy and cooperative relationships between patients / guardians / families / friends and healthcare providers, as well as sociocultural and legal responses to the laws of negligence and misconduct, including redress, retribution, remediation and apology Laws. The bio-ethical principles of non-maleficence, autonomy, beneficence, and justice provided the general framework for these discussions [8].

\section{DISCUSSION}

Being member of ethical committee should conscious about ethical challenges. Follow the valuebased system that focus on patient care about morals, action and their consequences. All of principle of ethical decision making must be followed. As a decision maker, should be honest, loyal, self-aware and courageous. Decision should be made that have positive impact on others.

Mindfulness refers to the knowledge of a person both internally (consciousness of their own thoughts) and externally (consciousness of what is happening in their environment). Individuals who are less aware of ethical challenges can fail to recognize or understand conflict of interest [9].
Organizational leaders face ethical risk challenges and stresses. The management of this ethical threat is challenging given the complexities of contemporary organizations [10]. Research suggests that standardized rules-based ethics systems are less successful in achieving positive ethical results than less formal values-based programs. A rule-based approach mainly focuses on issues of compliance: prevention, detection, and punishment of rules violations. As a result, rules-based programs tend to motivate people to try to avoid punishment. On the other hand, an approach based on values seeks to create and establish corporate principles and to enable workers to hold on to moral expectations and act on them. Such systems seek to build an environment that encourages workers to be mindful of ethical issues. Value-based programs seek to ensure that employees care about morals and shared values by words and consistent actions, rather than fear of doing wrong [11].

The relationship between moral intensity and ethical decision making is important. Individuals face morally complex circumstances, their consciousness of the moral conflict, their decisions on choices and consequences, and their ability to act are significantly affected by the particular aspects of the moral situation. The significant effect of proximity on moral awareness indicates that the closer an individual feels to the individual(s) influenced by his / her acts, the more likely he / she is to be aware of the moral problem. The moral judgment of the team members and their intention to act were strongly linked to the magnitude of consequences and the possibility of effect. This finding suggests that as individuals make decisions and form desires, they consider the consequences of their actions, both the degree to which their actions may cause harm or profit, and the probability that the consequences would occur [12].

\section{CONCLUSION}

Ethics is very important in decision making. Ethical decision making process help the individual to solve moral issue. Rest model of ethical decision making is easily applicable to moral dilemas. While solving an issue, must follow the prinicple of ethical decision making inculding autonomy, justice, benficence, nonmaleficence, feildety and veracity. All dimension of moral intensity effect the each compnent of decision making. 


\section{REFERENCES}

1. Sari, D., Baysal, E., Celik, G. G., \& Eser, I. (2018). Ethical Decision-Making Levels of Nursing Students. Pakistan journal of medical sciences, 34(3), 724.

2. Dunsford, J. (2015). Ethical Decision-making Framework: Evidence Informed Practice Tool. WRHA Ethics Services.

3. Abdool. R. (2004). A Principle Based Framework for Ethical Decision Making. Centre for Clinical Ethics at Hôtel-Dieu Grace Healthcare

4. Rest, J. R. (Ed.). (1994). Moral development in the professions: Psychology and applied ethics. Psychology Press

5. Reynolds, S. (2006). Moral awareness and ethical predispositions: Investigating the role of individual differences in the recognition of moral issues. Journal of Applied Psychology, 91, 233-243.

6. Jones, T. (1991).'Ethical Decision Making by Individuals in Organizations: An Issue-Contingent Model', Academy of Management Review 16(2), 366-395
7. Kupfer, J. M., \& Bond, E. U. (2012). Patient satisfaction and patient-centered care: necessary but not equal. Jama, 308(2), 139-140.

8. Potempa, A. (2018). Links between Medical Mistakes and Social Injustice. An Exploration. International Journal of Humanities and Cultural Studies (IJHCS) ISSN 23565926, 4(4), 218-231.

9. Ruedy, N. E., \& Schweitzer, M. E. (2010). In the moment: The effect of mindfulness on ethical decision making. Journal of Business Ethics, 95(1), 73-87.

10. Thiel, C. E., Bagdasarov, Z., Harkrider, L., Johnson, J. F., \& Mumford, M. D. (2012). Leader ethical decision-making in organizations: Strategies for sensemaking. Journal of Business Ethics, 107(1), 49-64.

11. Schminke, M., Arnaud, A., \& Kuenzi, M. (2007). The power of ethical work climates. Organizational Dynamics, 36(2), 171-186.

12. Lincoln, S. H., \& Holmes, E. K. (2011). Ethical decision making: A process influenced by moral intensity. Journal of Healthcare, Science and the Humanities, 1(1), 55-69. 